19,03

\title{
Теплопроводность кристаллов антимонида галлия в условиях всестороннего сжатия
}

\author{
(C) С.М. Лугуев, Н.Л. Крамынина, Н.В. Лугуева \\ Институт физики им. Х.И. Амирханова ДагНЦ, РАН, \\ Махачкала, Россия \\ E-mail: luguev.if@mail.ru
}

(Поступила в Редакцию 10 августа 2016 г.)

\begin{abstract}
Экспериментальные исследования теплопроводности монокристаллических и поликристаллических образцов антимонида галлия выполнены абсолютным методом при стационарном тепловом режиме в диапазоне температур 273-423K и в условиях всестороннего сжатия при давлениях от атмосферного до $0.35 \mathrm{GPa}$. Выявлены механизмы, ответственные за перенос тепла в указанных условиях. Определен параметр Бриджмена, характеризующий объемную зависимость теплопроводности. Показано, что различие в абсолютной величине коэффициента теплопроводности монокристалла и поликристаллов связано с процессами рассеяния фононов дефектами в приграничных слоях кристаллитов. Установлена корреляция между величиной коэффициента теплопроводности при всестороннем сжатии и изменением фононного спектра и упругой анизотропии кристаллов.
\end{abstract}

DOI: 10.21883/FTT.2017.03.44179.327

\section{1. Введение}

Антимонид галлия $(\mathrm{GaSb})$ ввиду простой кубической структуры типа цинковой обманки и свойств его зонной структуры может рассматриваться как модельный материал для фундаментальных исследований, в частности для исследования процессов переноса тепла, связанных с динамикой кристаллической решетки. Особый интерес кристаллы GaSb вызывают в связи с изучением механизмов переноса тепла в условиях всестороннего сжатия, поскольку представляют собой соединение с хорошо изученным фононным спектром [1-8], упругими модулями [8-12] и их зависимостями от давления [3-5,9]. Кроме того, интерес к изучению $\mathrm{GaSb}$ поддерживается его востребованностью в производстве оптоэлектронных приборов инфракрасного диапазона, в термофотоэлектрических генераторах и других технических устройствах [13-16]. Некоторые сведения о коэффициенте теплопроводности $\kappa$ антимонида галлия под давлением содержатся в работах [17-19], однако недостаточно изучено влияние структуры материала на процессы переноса тепла и нет данных о влиянии особенностей фононного спектра на его теплопроводность.

Цель настоящей работы состоит в экспериментальном исследовании коэффициента теплопроводности $\mathrm{GaSb}$, его температурной зависимости и определении характера объемной зависимости теплопроводности в условиях всестороннего сжатия. Представляет также интерес изучение влияния особенностей фононного спектра $\mathrm{GaSb}$ и структуры материала на величину и температурную зависимость $\kappa$ под давлением.

\section{2. Методика эксперимента}

Исследования выполнялись на монокристаллах $\mathrm{GaSb}$ $n$-типа проводимости с концентрацией свободных носителей тока $3.58 \cdot 10^{17} \mathrm{~cm}^{-3}$ и поликристаллах $p$-типа проводимости с концентрацией носителей тока $1.18 \cdot 10^{16} \mathrm{~cm}^{-3}$ при температуре $T=300 \mathrm{~K}$. Монокристаллы, выращенные методом Чохральского, были получены из НИИ „Гиредмет“ (Москва) с паспортными данными. Поликристаллы синтезированы в лабораторных условиях методом сплавления компонентов в горизонтальной муфельной печи в запаянных ампулах из кварцевого стекла, предварительно откачанных до $0.13 \mathrm{~Pa}$. Температура в муфельной печи поднималась постепенно со скоростью $6 \mathrm{~K} / \mathrm{min}$ до $1075 \mathrm{~K}$, и при этой температуре расплав при вибрационном перемешивании выдерживался в течение $2 \mathrm{~h}$. Затем температура в печи снижалась до $670 \mathrm{~K}$ со скоростью $3 \mathrm{~K} / \mathrm{min}$. При достижении $670 \mathrm{~K}$ печь отключалась, и в течение $12 \mathrm{~h}$ температура печи c ампулой снижалась до комнатной. Полученные таким образом поликристаллы имели р-тип проводимости, концентрацию носителей тока $1.18 \cdot 10^{16} \mathrm{~cm}^{-3}$ и подвижность носителей тока $682 \mathrm{~cm}^{2} / \mathrm{V} \cdot \mathrm{s}$ при $300 \mathrm{~K}$ (поликристаллы I). Часть полученных кристаллов была подвергнута отжигу при $670 \mathrm{~K}$ в течение 30 суток (поликристаллы II). Фазовый состав и структура образцов контролировались с помощью металлографического, рентгеноструктурного и термического анализа. Для выявления микроструктуры использовались следующие травители: концентрированная азотная кислота или пятипроцентный раствор хлорного железа в разбавленной в соотношении $1: 2$ соляной кислоте. По данным металлографических измерений средний размер зерен поликристаллов I составлял $\sim 1 \mathrm{~mm}$, а поликристаллов II - $3 \mathrm{~mm}$. Рентгенографические исследования проводились на установке ДРОН-2.0. Образцы имели кубическую структуру типа сфалерита. Поликристаллические образцы исследовались непосредственно после кристаллизации (поликристалл I) и после гомогенизирующего отжига (поликристалл II). 
Коэффициент теплопроводности антимонида галлия в зависимости от температуры и давления определялся нами абсолютным компенсационным методом при стационарном тепловом режиме $[18,20]$. Исследования $\kappa$ осуществлялись как в изобарических условиях в температурном интервале $273-423 \mathrm{~K}$, так и в изотермических условиях в интервале давлений от атмосферного до $0.35 \mathrm{GPa}$. Измерения $\kappa$ проводились как при повышении, так и при понижении давления в установке. Гистерезиса и остаточных явлений после снятия давления не обнаружено.

Суммарная средне-квадратическая погрешность измерения коэффициента теплопроводности на данной экспериментальной установке не превышает 4-6\% в зависимости от среды, передающей давление, теплопроводности исследуемого материала и области температур.

Одновременно с измерениями теплопроводности на экспериментальной установке выполнялись измерения электропроводности $\sigma$ и термоэдс $\alpha$ образцов $\mathrm{GaSb}$, изготовленных из того же материала, что и для измерения $\kappa$.

\section{3. Результаты и их анализ}

Полученные экспериментальные данные о коэффициенте теплопроводности монокристаллов и поликристаллов I и II антимонида галлия при атмосферном давлении и давлении $0.35 \mathrm{GPa}$ представлены на рис. 1-3. Для выяснения механизмов теплопереноса в $\mathrm{GaSb}$, как уже отмечалось, одновременно с измерениями теплопроводности выполнены измерения электропроводности и термоэдс. По этим данным оценивалось участие носителей тока в переносе тепла. Электронная компонента теплопроводности вычислялась по закону Видемана-Франца $\kappa_{e}=L \sigma T$. Число Лоренца $L$ определялось по формуле для параболической зоны с привлечением экспериментальных данных по $\alpha$ в предположении, что рассеяние носителей тока происходит на акустических колебаниях кристаллической решетки. Расчеты электронной составляющей теплопроводности показали, что ввиду малой концентрации носителей тока в исследованном интервале температур и давлений ее величина не превышает $0.7 \%$ от общей теплопроводности. Следовательно, в изученных образцах $\mathrm{GaSb}$ основным механизмом теплопереноса, определяющим абсолютную величину, температурную и барическую зависимости теплопроводности, являются колебания кристаллической решетки, т.е. фононы. Соответственно данные на рис. 1-3 являются температурными и барическими зависимостями теплопроводности решетки.

Теплопроводность поликристаллов как при атмосферном давлении, так и при всестороннем сжатии значительно ниже, чем в случае монокристаллического образца, причем теплопроводность поликристалла II (отожженный образец) несколько выше, чем для поликристалла I. Как видно из рисунков 1-3, теплопровод-

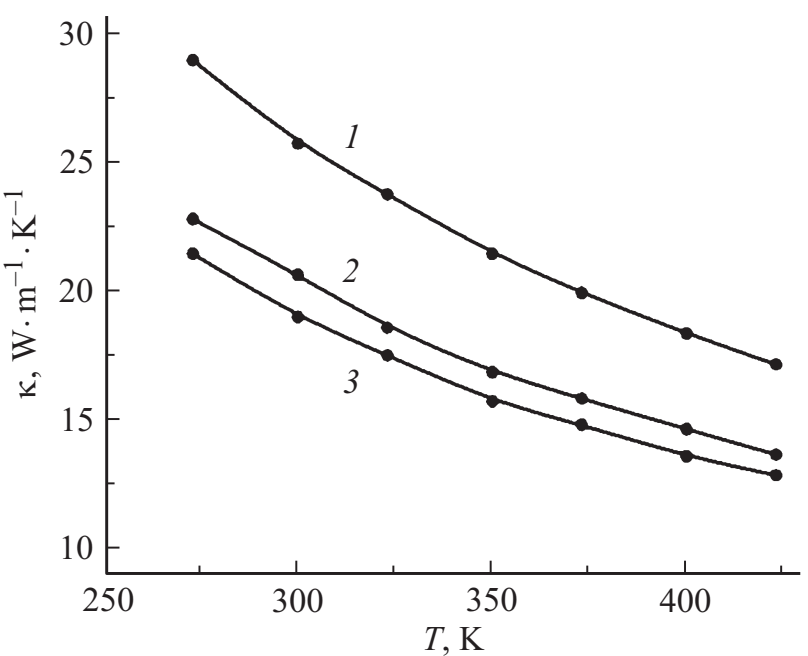

Рис. 1. Температурные зависимости коэффициента теплопроводности $\mathrm{GaSb}$ при атмосферном давлении. 1 - монокристалл, 2 - поликристалл II, 3 - поликристалл I.

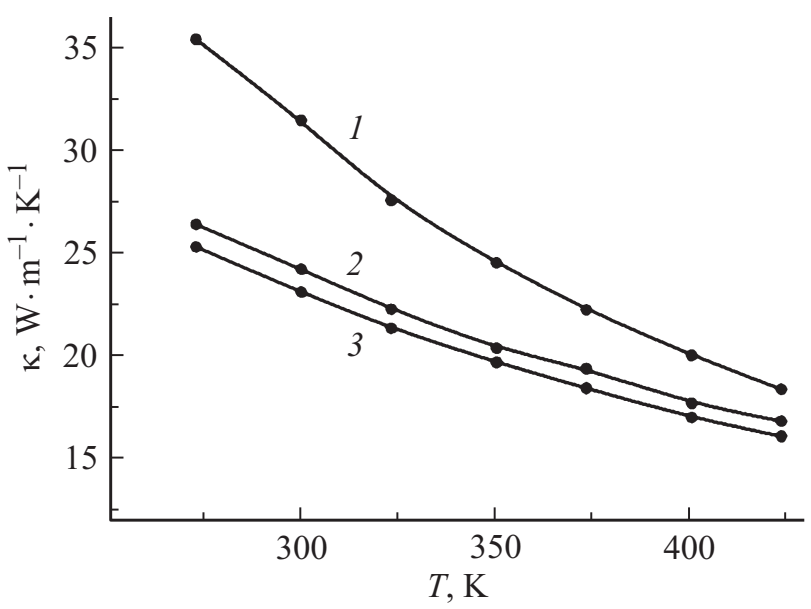

Рис. 2. Температурные зависимости коэффициента теплопроводности $\mathrm{GaSb}$ при давлении $0.35 \mathrm{GPa} .1$ - монокристалл, 2 - поликристалл II, 3 - поликристалл I.

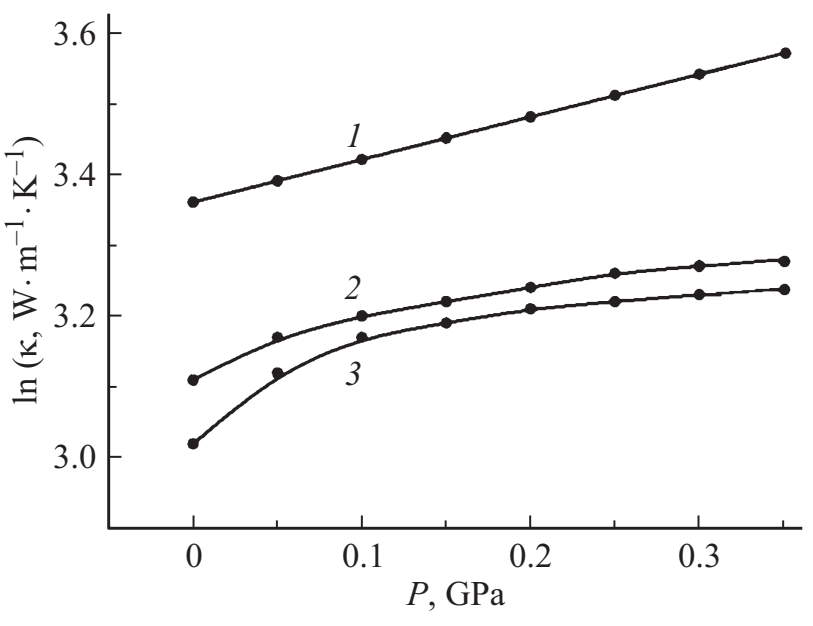

Рис. 3. Барические зависимости при 273 К коэффициента теплопроводности GaSb. 1 - монокристалл, 2 - поликристалл II, 3 - поликристалл I. 
Таблица 1. Частоты, температуры Дебая, пики плотности состояний, скорости фононов, параметры Грюнайзена для различных фононных ветвей $\mathrm{GaSb}$

\begin{tabular}{c|c|c|c|c|c}
\hline $\begin{array}{c}\text { Фононные } \\
\text { ветви }\end{array}$ & $\begin{array}{c}\text { Частота } \\
v_{\max } \text {, THz }[1]\end{array}$ & $\begin{array}{c}\text { Температура } \\
\text { Дебая } \theta_{i}, \mathrm{~K}\end{array}$ & $\begin{array}{c}\text { Пики плотности } \\
\text { состояний, K [1] }\end{array}$ & $\begin{array}{c}\text { Скорость } \\
\text { фононов } v, \mathrm{~m} / \mathrm{s}[9]\end{array}$ & $\begin{array}{c}\text { Параметр } \\
\text { Грюнайзена, } \gamma_{i}[2]\end{array}$ \\
\hline TA & 1.70 & 82 & 82 & 2770 & 0.49 \\
LA & 4.99 & 239 & 209 & 3970 & 1.41 \\
TO & 6.87 & 330 & 278 & & 1.72 \\
LO & 7.20 & 476 & 320 & & 1.72
\end{tabular}

ность монокристалла и поликристаллических образцов различной технологической предыстории во всем исследованном диапазоне температур с повышением температуры снижается, а при всестороннем сжатии значения $\kappa$ образцов существенно выше, чем без приложенного давления. При атмосферном давлении температурная зависимость фононной теплопроводности исследованных образцов $\mathrm{GaSb}$ подчиняется закону $\kappa \propto T^{-n}$, где показатель степени близок к единице, что характерно для фонон-фононных процессов рассеяния в этой области температур. Рассеяние же фононов на дефектах при этих температурах вносит постоянный вклад в тепловое сопротивление.

Для анализа экспериментальных данных необходимы значения температур Дебая $\theta$, параметра Грюнайзена $\gamma$, дисперсионных соотношений для фононов исследуемого соединения. Поскольку кристаллическая ячейка $\mathrm{GaSb}$ содержит два атома, в антимониде галлия существует шесть фононных ветвей: две поперечные акустические (TA), продольная акустическая (LA), две поперечные оптические (ТO) и продольная оптическая (LO). Данные по частотам, групповой скорости, температуре Дебая и параметру Грюнайзена для различных ветвей фононного спектра GaSb приведены в табл. 1. Температуры Дебая рассчитаны по данным работы [1].

Проведена оценка длины свободного пробега фононов при фонон-фононных процессах рассеяния по формуле [21]

$$
l_{\mathrm{ph}-\mathrm{ph}}=\frac{a}{\beta \gamma T},
$$

где $a^{3}$ - объем, приходящийся на один атом; $\beta-$ коэффициент теплового расширения, $\gamma$ - параметр Грюнайзена, усредненный для всех фононных ветвей. Данные для $\beta$ взяты из работы [22]. Величина $\gamma$ определена с помощью выражения [23]

$$
\gamma=\frac{2 \gamma_{\mathrm{TA}} \theta_{\mathrm{TA}}+\gamma_{\mathrm{LA}} \theta_{\mathrm{LA}}+2 \gamma_{\mathrm{TO}} \theta_{\mathrm{TO}}+\gamma_{\mathrm{LO}} \theta_{\mathrm{LO}}}{2 \theta_{\mathrm{TA}}+\theta_{\mathrm{LA}}+2 \theta_{\mathrm{TO}}+\theta_{\mathrm{LO}}} .
$$

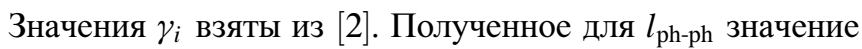
равно $4 \cdot 10^{-8} \mathrm{~m}$. Поскольку эта величина на несколько порядков меньше размеров кристаллитов в поликристаллах, более низкую теплопроводность поликристаллов невозможно объяснить рассеянием фононов границами. Низкая теплопроводность поликристаллов по сравнению с монокристаллическим образцом (рис. 1-3) может быть обусловлена рассеянием фононов на дефектах в приграничных областях зерен поликристаллов. В результате длительного отжига в поликристалле II наблюдается некоторый рост размеров зерен, и при этом количество дефектов в образце уменьшается. В результате этого теплопроводность поликристалла II несколько выше, чем для поликристалла I.

Проанализируем участие в теплопереносе различных фононных ветвей, следуя модели, использованной в работах $[23,24]$. Предполагается, что не все акустические фононы имеют скорость $v$, указанную в табл. 1 . Эту скорость имеют только фононы с длиной волны, большей некоторой граничной длины волны $\lambda_{b}$. Именно эта часть фононов переносит тепло. Фононы же с меньшей длиной волны имеют нулевую скорость и в теплопереносе не участвуют. Граничная длина волны для акустических фононов определяется выражением [23]

$$
\lambda_{b}=\frac{v}{v_{\max }},
$$

где $v$ - скорость фононов, $v_{\max }-$ максимальная частота данной акустической фононной ветви. Рассчитанная нами по этой формуле граничная длина волны составляет $16.4 \AA$ для ТА-фононов и $7.95 \AA$ для LA-фононов. Длине волны $\lambda_{b}$ соответствуют волновой вектор $q_{b}=2 \pi / \lambda_{b}$, и переносящие тепло фононы должны находиться внутри сферы с центром, совпадающим с центром первой зоны Бриллюэна, и радиусом $q_{b}$. Средний радиус первой зоны Бриллюэна [23]

$$
q_{m}=(3 / \pi)^{1 / 3}\left(2 \pi / a_{0}\right),
$$

где $a_{0}-$ постоянная решетки. Число фононов пропорционально объему зоны Бриллюэна, в котором они расположены. Часть фононов, имеющих большую скорость и участвующих в теплопереносе, равна $\left(q_{b} / q_{m}\right)^{3}$. Из этого соотношения нами было рассчитано, что в $\mathrm{GaSb}$ часть фононов, переносящих тепло, составляет $\sim 5 \%$ для ТА-ветви и $\sim 47 \%$ для LA-ветви. Остальные акустические фононы имеют значительно меньшую скорость. Дополнительно необходимо учесть, что скорость LA-фононов выше, чем TA-фононов. Таким образом, можно считать, что в антимониде галлия LA-фононы вносят преобладающий вклад в теплоперенос и определяют температурную и барическую зависимости коэффициента теплопроводности. 
Влияние оптических фононов на теплоперенос определяется соотношением масс атомов в элементарной ячейке $\varepsilon=M_{1} / M_{2}$, которое определяет форму дисперсионной кривой для оптических фононов, а следовательно, их скорость и величину энергетической щели между акустическими и оптическими ветвями. Как показывают теоретические расчеты [7], при $\varepsilon<2$ вклад оптических фононов в теплоперенос не превышает 4\%. Для антимонида галлия $\varepsilon=1.75$, и ввиду этого участие оптических фононов в теплопереносе незначительно. Из дисперсионных кривых для GaSb (см., например, [1]) также видно, что скорость оптических фононов близка к нулю, следовательно, тепло они не переносят. В то же время, как показано в $[7,25,26]$, при $\varepsilon<2$ важным является рассеяние акустических фононов на оптических.

Исходя из изложенного выше можно сделать вывод, что в исследованной области температур в $\mathrm{GaSb}$ пере-

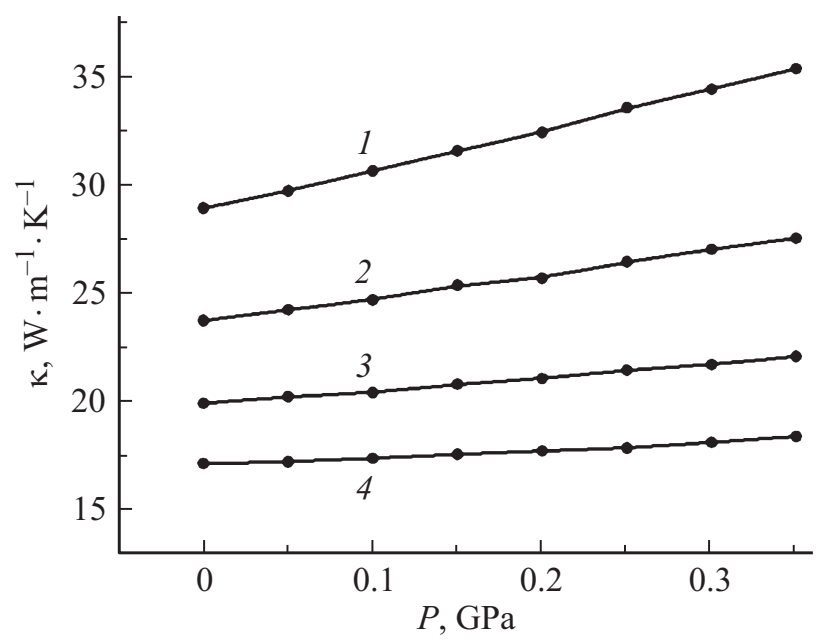

Рис. 4. Барические зависимости коэффициента теплопроводности монокристалла $\mathrm{GaSb}$ при фиксированных температурах. $T, \mathrm{~K}: 1-273,2-323,3-373,4-423$.

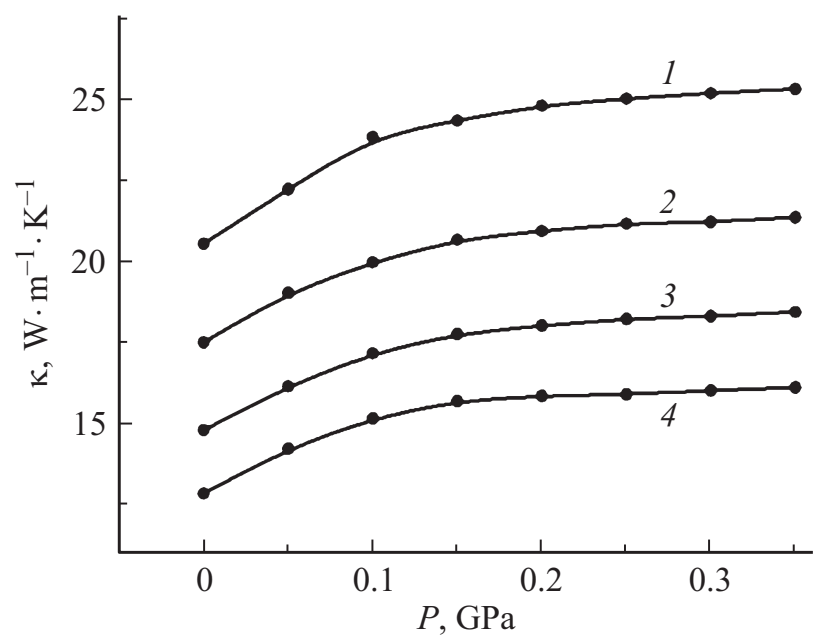

Рис. 5. Барические зависимости коэффициента теплопроводности поликристалла I антимонида галлия при фиксированных температурах. $T$, K: $1-273,2-323,3-373,4-423$.
Таблица 2. Параметр Бриджмена g для монокристалла и поликристаллов $\mathrm{GaSb}$ по данным эксперимента

\begin{tabular}{c|c|c|c}
\hline$T$, К & Монокристалл & Поликристалл I & Поликристалл II \\
\hline 273 & 31 & 11 & 14 \\
323 & 25 & 10 & 12 \\
373 & 16 & 9 & 10 \\
423 & 14 & 8 & 9
\end{tabular}

нос тепла осуществляется в основном LA-фононами, а роль ТА- и оптических фононов сводится к рассеянию LA-фононов.

На рис. 3 представлены барические зависимости $\kappa$ монокристалла и поликристаллов $\mathrm{GaSb}$ при $273 \mathrm{~K}$. Как видно из этого рисунка, теплопроводность монокристалла и поликристаллов $\mathrm{GaSb}$ растет с повышением давления. Изменение теплопроводности кристаллов, подвергнутых всестороннему сжатию, происходит вследствие уменьшения объема кристалла и обусловленного этим изменения частот колебаний решетки, ангармонизма связей, увеличения сил взаимодействия между атомами. Объемная зависимость теплопроводности выражается параметром Бриджмена [24]

$$
g=-\left(\frac{\partial \ln \kappa}{\partial \ln V}\right)_{T}=B_{T}\left(\frac{\partial \ln \kappa}{\partial P}\right)_{T},
$$

где $B_{T}$ - изотермический модуль объемного сжатия, $V$ - объем, $P$ - давление. На основе экспериментальных данных для барических зависимостей коэффициента теплопроводности (рис. 4 и 5) по этой формуле рассчитан параметр Бриджмена монокристалла и поликристаллов $\mathrm{GaSb}$ для четырех температур: 273, 323, 373 и $423 \mathrm{~K}$. Полученные результаты приведены в табл. 2. Значения модуля объемного сжатия взяты из работы [9]. Величина параметра Бриджмена монокристаллического $\mathrm{GaSb}$ при $273 \mathrm{~K}$ равна 31. С повышением температуры величина $g$ снижается и составляет 25, 16, 14 для температур 323, 373 и $423 \mathrm{~K}$ соответственно. В поликристаллах - как неотожженных, так и подвергнутых отжигу — в области давлений $0.15-0.35 \mathrm{GPa}$ значение параметра Бриджмена близко к 10 и слабо зависит от температуры.

Сравним экспериментально полученную величину $g$ с данными теоретических расчетов. Согласно формуле Лейбфрида-Шлемана [24] в области температуры Дебая и выше теплопроводность решетки может быть определена выражением

$$
\kappa \propto a \theta^{3} \gamma^{-2}
$$

где $a^{3}-$ средний объем, занимаемый одним атомом, $\theta$ и $\gamma$ - средние значения температуры Дебая и параметра Грюнайзена для всех фононных ветвей, участвующих в теплопереносе. Дифференцирование формулы (6) дает 
следующее выражение для параметра Бриджмена:

$$
g=-\left(\frac{\partial \ln \kappa}{\partial \ln V}\right)_{T}=-3\left(\frac{\partial \ln \theta}{\partial \ln V}\right)_{T}+2\left(\frac{\partial \ln \gamma}{\partial \ln V}\right)-\frac{1}{3},
$$

где $\gamma=-(\partial \ln \theta / \partial \ln V)$, а объемная зависимость параметра Грюнайзена определяется как $q=(\partial \ln \gamma / \partial \ln V)_{T}$. Следовательно, $g=3 \gamma+2 q-1 / 3$. Согласно [23], $q \approx \gamma$ и

$$
g=5 \gamma-1 / 3
$$

Поскольку теплоперенос в $\mathrm{GaSb}$ осуществляют LAфононы, значения $\gamma$ при расчетах $g$ возьмем для этой же фононной ветви. Получается, что $g=6.7$. Это значительно ниже величин $g$, полученных из экспериментальной зависимости $\ln \kappa=f(P)$ (табл. 2).

Как видно из табл. 2, параметр Бриджмена снижается с температурой, что отличается от температурной зависимости $g$ для $\mathrm{CuCl}$ [23], солей щелочных металлов [25] и $\mathrm{ZnS}$ [27], в которых наблюдался рост $g$ при возрастании температуры, объяснявшийся авторами увеличением участия LA-фононов в теплопереносе.

Аномально высокая величина $g$ в монокристалле GaSb при температурах 273 и $323 \mathrm{~K}$, а также ее температурная зависимость определяются особенностями фононного спектра этого соединения. В $\mathrm{GaSb}$ пики плотности состояний оптических фононов приходятся на $278 \mathrm{~K}$ (ТО-ветвь) и $320 \mathrm{~K}$ (LO-ветвь) [1]. Поскольку в $\mathrm{GaSb}$ оптические фононы рассеивают переносящие тепло акустические фононы, в температурной области $T>270 \mathrm{~K}$ это рассеяние сказывается на величине теплопроводности, снижая ее. При увеличении всестороннего давления частоты фононов смещаются: высокочастотные в область более высоких частот, низкочастотные в область низких частот [3-5]. Это приводит к увеличению энергетической щели между акустическими и оптическими фононами. В результате этого снижается вероятность рассеяния акустических фононов оптическими, теплопроводность возрастает с давлением, и параметр Бриджмена превышает значения, рассчитанные по формуле (8). При 273 и $323 \mathrm{~K}$ дополнительное увеличение теплопроводности с давлением происходит вследствие смещения частот оптических фононов в область более высоких энергий и снижения их числа. Этот эффект существеннее при $273 \mathrm{~K}$, чем при $323 \mathrm{~K}$, о чем свидетельствует изменение $g$ с температурой. При 373 и $423 \mathrm{~K}$ смещение частот оптических фононов с давлением не снижает числа возбужденных оптических фононов, поскольку все оптические фононы уже возбуждены. Рассеяние с участием оптических фононов при этих температурах снижается только вследствие увеличения энергетической щели, и величина $g$, определенная по экспериментальным данным, выше значений, полученных из расчетов по формуле (8), но значительно ниже, чем при 273 и $323 \mathrm{~K}$.

Формула (8) наряду со снижением фонон-фононного рассеяния ввиду смещения с давлением пиков плотности состояний фононов не учитывает также существования в кристаллах упругой анизотропии $\xi=C_{11} / C_{44}$ и ее изменения с давлением. В работе [28] показано, что существует корреляция между теплопроводностью кристаллической решетки и величиной $\xi$, характеризующей преобладание осевой поляризации над продольнопоперечной поляризацией. При увеличении $\xi$ снижается вероятность рассеяния акустических фононов акустическими, и теплопроводность возрастает [28]. Поскольку в $\mathrm{GaSb}$ производная по давлению для $C_{11}$ почти в 5 раз выше, чем для $C_{44}[9,12]$, с ростом давления растет упругая анизотропия и соответственно теплопроводность, что приводит к росту параметра Бриджмена.

Барические зависимости $\kappa$ для поликристаллов $\mathrm{GaSb}$ (рис. 5) немонотонны: максимальный рост теплопроводности происходит при возрастании давления до $0.10 \mathrm{GPa}$. При дальнейшем росте давления теплопроводность возрастает почти линейно с более низким барическим коэффициентом, чем в монокристалле. Различие в абсолютной величине коэффициента теплопроводности и ее барической зависимости монокристаллов и поликристаллов определяется процессами рассеяния фононов в приграничных слоях кристаллитов, составляющих поликристалл. Искаженные зоны вблизи границ кристаллитов являются скоплениями, источниками и стоками дефектов [29]. При гидростатическом сжатии на межкристаллитных границах возникают напряженные состояния, связанные с наличием углов разориентации кристаллитов. Каналом релаксации таких состояний являются дислокации несоответствия [30]. Граница в условиях всестороннего сжатия становится источником дополнительных дислокаций, возникающих в результате деформаций и усиления термоактивационных процессов при росте давления. В результате появления на границах кристаллитов дополнительных дислокаций происходит усиление рассеяния фононов и ослабление роста теплопроводности в поликристаллах с ростом давления по сравнению с монокристаллами. В исследованных нами поликристаллах $\mathrm{GaSb}$ это проявилось в том, что барический коэффициент теплопроводности в них ниже, чем у монокристаллов $\mathrm{GaSb}$. Отжиг способствует росту зерен поликристалла, снижению роли границ и дополнительного рассеяния фононов. Барический коэффициент теплопроводности отожженных поликристаллов $\mathrm{GaSb}$ несколько выше, чем у неотожженных (табл. 2).

\section{4. Заключение}

Экспериментальное исследование барической зависимости теплопроводности монокристаллов и поликристаллов $\mathrm{GaSb}$ в условиях всестороннего сжатия позволило определить параметр Бриджмена. Получение по экспериментальным данным более высоких значений $g$, чем рассчитанные из теоретических представлений, обусловлено уменьшением вклада процессов фонон-фононного рассеяния в тепловое сопротивление в результате сдви- 
гов пиков плотностей состояний фононов и увеличения упругой анизотропии при всестороннем сжатии. Аномально высокие значения $g$ монокристаллов при 273 и $323 \mathrm{~K}$ связаны с особенностями фононного спектра $\mathrm{GaSb}$, приводящими с ростом давления к снижению числа оптических фононов, на которых рассеиваются переносящие тепло акустические фононы. Более низкая, чем у монокристалла, теплопроводность поликристаллов I и II связана с процессами рассеяния фононов в приповерхностных областях кристаллитов. Теплопроводность отожженного поликристалла II несколько выше, чем у поликристалла I. Уменьшение абсолютной величины барического коэффициента теплопроводности поликристаллов $\mathrm{GaSb}$ обусловлено появлением дополнительных дислокаций на границах кристаллитов с ростом всестороннего сжатия.

\section{Список литературы}

[1] M.K. Farr, J.G. Traylor, S.K. Sinha. Phys. Rev. B 11, 1587 (1975).

[2] T. Soma, Y. Saito, H. Matsuo. Phys. Status Solidi B 103, K173 (1981).

[3] K. Aoki, E. Anastassakis, M. Cardona. Phys. Rev. B 30, 681 (1984).

[4] S. Klotz, M. Braden, J. Kulda, P. Pavone, B. Steinninger. Phys. Status Solidi B 223, 441 (2001).

[5] S. Shinde, M. Talati, P.K. Jha, S.P. Sanyal. Pramana 63, 425 (2004).

[6] K.K. Mishra, K.S. Upadhyaya. Int. J. Sci. Eng. Res. 3, 1 (2012).

[7] A. Jain, A.J.H. McGaughey. J. Appl. Phys. 116, 073503 (2014).

[8] J. Buckeridge, D.O. Scanlon, T.D. Veal, A. Walsh, C.R.A. Catlow. Phys. Rev. B 89, 014107 (2014).

[9] H.J. McSkimin, A. Jayaraman, P. Andreatch, T.B. Bateman. J. Appl. Phys. 39, 4127 (1968).

[10] W.F. Boyle, R.J. Sladek. Phys. Rev. B 11, 2933 (1975).

[11] R.K. Singh, R.D. Singh. Phys. Statis Solidi B 114, 235 (1982).

[12] A.R. Jivani, A.R. Jani. Turk. J. Phys. 36, 215 (2012).

[13] P.S. Dutta, H.L. Bhat, V. Kumar. J. Appl. Phys. 81, 5821 (1997).

[14] O.V. Sulima, A.W. Bett. Solar Energy Mater. Solar Cells 66, 533 (2001).

[15] L.M. Fraas, J.E. Avery, H.X. Huang. Semicond. Sci. Technol. 18, S247 (2003).

[16] В.П. Хвостиков, С.В. Сорокина, Н.С. Потапович, О.А. Хвостикова, А.В. Малевская, А.С. Власов, М.З. Шварц, Н.Х. Тимошина, В.М. Андреев. ФТП 44, 270 (2010).

[17] Х.И. Амирханов, Н.Л. Крамынина, С.Н. Эмиров. ФТТ 25, 2486 (1983).

[18] Sh.M. Ismailov, Ja.B. Magomedov, N.L. Kramynina. High Temp. High Press. 26, 657 (1994).

[19] С.Н. Эмиров, А.Э. Рамазанова. Изв. РАН. Сер. физ. 77, 317 (2013).

[20] Н.Л. Крамынина, С.М. Лугуев, Н.В. Лугуева, С.Н. Эмиров. Методика ГСССД МЭ 250-2016. Деп. в ФГУП „ВНИИМС“ 09.06.2016 г. № 243a-2016 кк.

[21] Р. Берман. Теплопроводность твердых тел. Мир, М. (1979). $286 \mathrm{c}$.
[22] E.F. Steigmeier, I. Kudman. Phys. Rev. 141, 767 (1966).

[23] G.A. Slack, P. Andersson. Phys. Rev. B 26, 1873 (1982).

[24] G.A. Slack. In: Solid State Physics. Academic Press, N. Y. (1979). V. 34. P. 1.

[25] G.A. Slack, R.G. Ross. J. Phys. C 18, 3957 (1985).

[26] Е.Д. Девяткова, И.А. Смирнов. ФТТ 4, 2507 (1962).

[27] Н.В. Лугуева, Н.Л. Крамынина, С.М. Лугуев. ФТТ 43, 222 (2001).

[28] Ю.А. Логачев, Б.Я. Мойжес, А.В. Петров, Н.С. Цыпкина. ФТT 16, 2489 (1974).

[29] Ж.П. Сюше. Физическая химия полупроводников. Металлургия, М. (1969). 224 с.

[30] Э.П. Фельдман, В.А. Стрельцов. ФТТ 24, 466 (1982). 